\title{
Robust detection of immune transcripts in FFPE samples using targeted RNA sequencing
}

\author{
Benjamin E. Paluch ${ }^{1}$, Sean T. Glenn ${ }^{1,2}$, Jeffrey M. Conroy ${ }^{1,3}$, Antonios Papanicolau- \\ Sengos ${ }^{1}$, Wiam Bshara ${ }^{4}$, Angela R. Omilian ${ }^{4}$, Elizabeth Brese ${ }^{4}$, Mary Nesline ${ }^{1}$, Blake \\ Burgher $^{1}$, Jonathan Andreas ${ }^{1}$, Kunle Odunsi ${ }^{5}$, Kevin Eng ${ }^{6}$, Ji $\mathrm{He}^{1}$, Maochun Qin ${ }^{1}$, \\ Mark Gardner ${ }^{1}$, Lorenzo Galluzzi ${ }^{7,8,9,10,11,12}$, Carl D. Morrison ${ }^{1,3}$ \\ ${ }^{1}$ Omniseq LLC, Buffalo, NY 14203, USA \\ ${ }^{2}$ Department of Cancer Genetics, Roswell Park Cancer Institute, Buffalo, NY 14263, USA \\ ${ }^{3}$ Center for Personalized Medicine, Roswell Park Cancer Institute, Buffalo, NY 14263, USA \\ ${ }^{4}$ Department of Pathology, Roswell Park Cancer Institute, Buffalo, NY 14263, USA \\ ${ }^{5}$ Department of Gynecologic Oncology, Center for Immunotherapy, Department of Immunology, Roswell Park Cancer \\ Institute, Buffalo, NY 14263, USA \\ ${ }^{6}$ Department of Biostatistics, Roswell Park Cancer Institute, Buffalo, NY 14263, USA \\ ${ }^{7}$ Department of Radiation Oncology, Weill Cornell Medical College, New York, NY 10065, USA \\ ${ }^{8}$ Equipe 11 labellisée Ligue contre le Cancer, Centre de Recherche des Cordeliers, 75006 Paris, France \\ ${ }^{9}$ INSERM, U1138, 75006 Paris, France \\ ${ }^{10}$ Université Paris Descartes/Paris V, Sorbonne Paris Cité, 75006 Paris, France \\ ${ }^{11}$ Université Pierre et Marie Curie/Paris VI, 75006 Paris, France \\ ${ }^{12}$ Gustave Roussy Cancer Campus, 94805 Villejuif, France \\ Correspondence to: Carl D. Morrison, email: carl.morrison@omniseq.com \\ Keywords: cancer immunotherapy, CD8+ cytotoxic T lymphocytes, nivolumab, NY-ESO-1, PD-L 1
}

Received: October 21, $2016 \quad$ Accepted: November 21, 2016

Published: November 29, 2016

\section{ABSTRACT}

Current criteria for identifying cancer patients suitable for immunotherapy with immune checkpoint blockers (ICBs) are subjective and prone to misinterpretation, as they mainly rely on the visual assessment of CD274 (best known as PD-L1) expression levels by immunohistochemistry (IHC). To address this issue, we developed a RNA sequencing (RNAseq)-based approach that specifically measures the abundance of immune transcripts in formalin-fixed paraffin embedded (FFPE) specimens. Besides exhibiting superior sensitivity as compared to whole transcriptome RNAseq, our assay requires little starting material, implying that it is compatible with RNA degradation normally caused by formalin. Here, we demonstrate that a targeted RNAseq panel reliably profiles mRNA expression levels in FFPE samples from a cohort of ovarian carcinoma patients. The expression profile of immune transcripts as measured by targeted RNAseq in FFPE versus freshly frozen (FF) samples from the same tumor was highly concordant, in spite of the RNA quality issues associated with formalin fixation. Moreover, the results of targeted RNAseq on FFPE specimens exhibited a robust correlation with mRNA expression levels as measured on the same samples by quantitative RT-PCR, as well as with protein abundance as determined by IHC. These findings demonstrate that RNAseq profiling on archival FFPE tissues can be used reliably in studies assessing the efficacy of cancer immunotherapy. 


\section{INTRODUCTION}

During the past few years, no less than four distinct monoclonal antibodies (mAbs) that interrupt immunological checkpoints, so-called immune checkpoint blockers (ICBs) have been approved by the US Food and Drug Administration (FDA) for use in cancer patients as standalone immunotherapeutic regimens or combined with other drugs [1]. These agents include the cytotoxic T lymphocyte-associated protein 4 (CTLA4)-specific mAb ipilimumab (Yervoy), which is licensed for the treatment of melanoma [2-4]; two mAbs targeting programmed cell death 1 ( $\mathrm{PCDC} 1$; best known as PD-1), namely nivolumab (Opdivo) and pembrolizumab (Keytruda), which are approved for use in patients with melanoma, head and neck squamous cell carcinoma, non-small cell lung carcinoma (NSCLC) and Hodgkin's lymphoma [5-14]; and atezolizumab (Tecentriq), a mAb targeting CD274 (best known as PD-L1) recently approved for use in bladder carcinoma patients $[15,16]$. ICBs can mediate robust clinical effects as they release immune effectors from cancer-driven immunosuppression, hence activating novel or reactivating existing tumor-targeting immune responses [17]. However, only a limited fraction of patients (generally $<30 \%$ ) benefit from ICBs as standalone immunotherapeutic agents [1]. Moreover, it is estimated that the total market for ICBs may reach 7 billion US by 2020 [18]. Thus, there are both clinical and economical challenges associated with the growing use of ICBs, calling for the development of cost-effective and reliable selection procedures.

Currently, the immunohistochemical assessment of PD-L1 expression level on formalin-fixed paraffinembedded (FFPE) specimens is the only test employed in the clinic to guide the use of ICBs, and is an approved companion diagnostic for NSCLC patients considered for pembrolizumab treatment $[19,20]$. Other potential indicators of response to checkpoint inhibition include mutational burden [21-23] and tumor-infiltrating lymphocyte (TIL) abundance [24-26], but both lack sensitivity and specificity as single biomarkers. An alternative approach to predicting clinical response to ICBs involves digital gene expression analysis by RNA next generation sequencing (NGS). While this methodology works well on fresh frozen (FF) samples, it has demonstrated suboptimal performance on more readily available archival FFPE specimens $[27,28]$. Thus, there is no test available today to reliably predict whether a cancer patient will respond to immunotherapy with ICBs.

To begin to address this major gap in clinical care, we applied targeted amplicon-based RNA sequencing (RNAseq) to a panel of 395 transcripts related to T-cell receptor signaling (TCRS), tumor infiltration by immune cells, and other immunological functions that are key for anticancer immunosurveillance. RNAseq is particularly adept at detecting poorly represented transcripts. We optimized our assay for RNA isolated from FFPE samples, which suffer from RNA degradation as a result of formalin
A

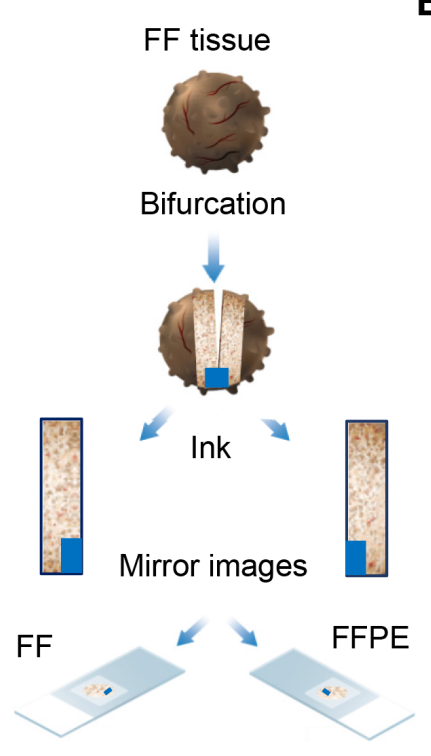

B

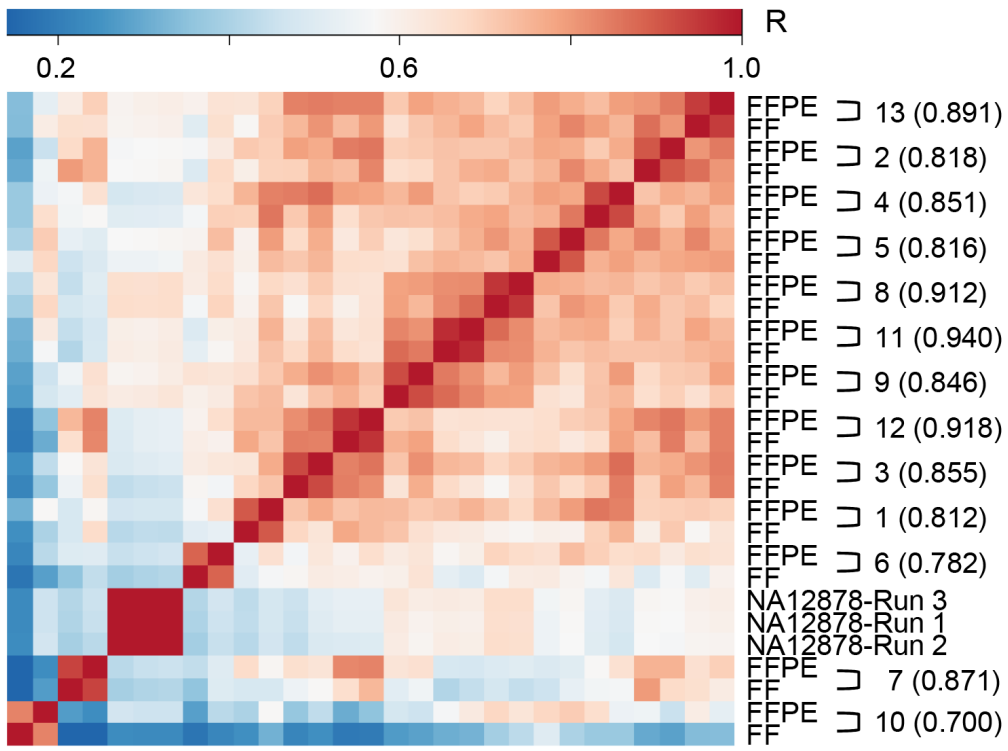

Figure 1: Immune Advance assay performance on FFPE versus FF samples. A. Samples from 14 ovarian cancer patients were halved to generate a series of matched fresh frozen (FF) and formalin-fixed paraffin embedded (FFPE) specimens, which were serially sectioned, and processed for further analysis. B. Targeted RNAseq on a panel of immunological transcripts was performed on 13 samples pairs that passed quality control upon RNA extraction, as well as on control sample NA12878 in triplicate runs. Each FFPE/FF sample pair demonstrated unique correlation distinct from all other specimens. The matrix depict inter-sample correlation based on Pearson correlation coefficient $(\mathrm{R})$. $\mathrm{R}^{2}$ are indicated for each sample pair in parentheses. 
A

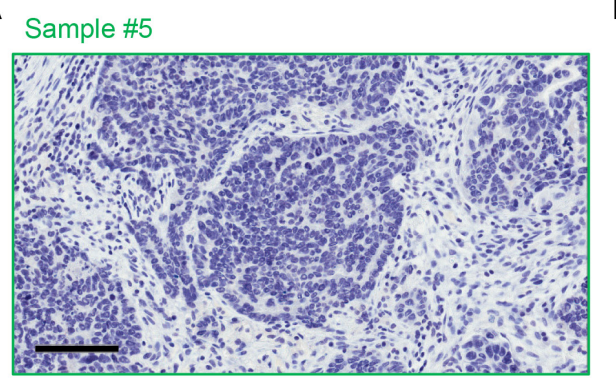

Sample \#7

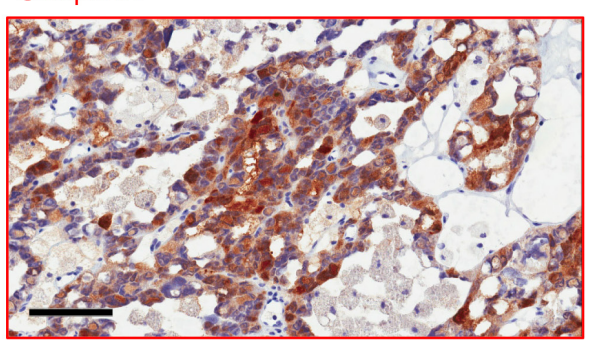

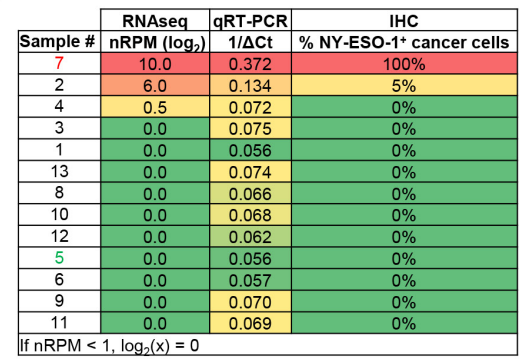

C

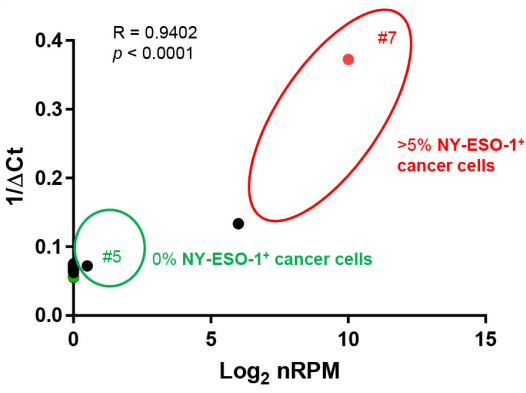

Figure 2: Validation of the Immune Advance assay on NY-ESO-1. A-C. Formalin-fixed paraffin embedded (FFPE) samples from 13 ovarian cancer patients were sectioned and processed for immunohistochemical assessment of NY-ESO-1 expression, RNA extraction followed by targeted RNAseq on a panel of immunological transcripts or qRT-PCR-assisted quantification of CTAG1B (NY-ESO-1-coding) mRNA levels (GAPDH expression was monitored as internal reference). A. Representative images of NY-ESO-1 expression levels as assessed by immunohistochemistry (IHC) on samples \#5 and \#7. Scale bars $=100 \mu \mathrm{m}$. B. Summary of results from RNAseq, qRT-PCR and IHC. C. Correlation of RNAseq ( $\log _{2}$-transformed normalized reads per million, nRPM) and qRT-PCR $(1 / \Delta C t)$ results. Samples $\# 5$ and \#7 are indicated; circles delineate samples with negative $(0 \%)$ or positive $(\geq 5 \%)$ NY-ESO-1 staining by IHC. Pearson correlation coefficient (R) and $p$ value are reported.

A

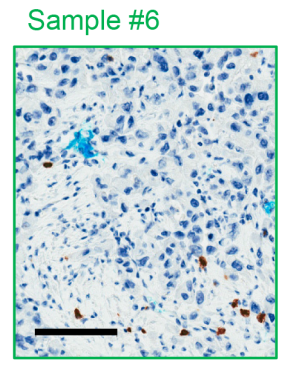

B
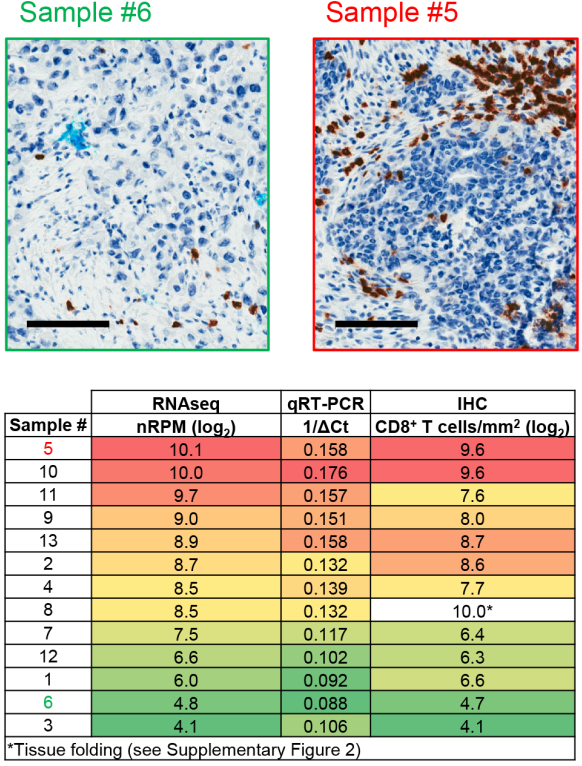

C

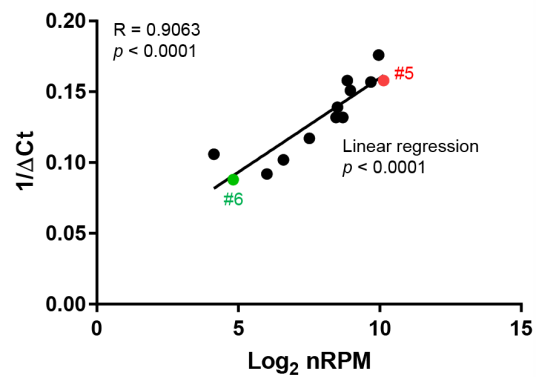

D

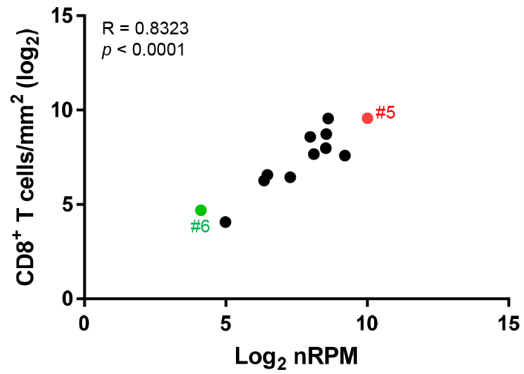

Figure 3: Validation of the Immune Advance assay on CD8. A-D. Formalin-fixed paraffin embedded (FFPE) samples from 13 ovarian cancer patients were sectioned and processed for immunohistochemical assessment of CD8 expression, RNA extraction followed by targeted RNAseq on a panel of immunological transcripts or qRT-PCR-assisted quantification of $C D 8$ mRNA levels ( GAPDH expression was monitored as internal reference). A. Representative images of $\mathrm{CD}^{+} \mathrm{T}$-cell infiltration as assessed by immunohistochemistry (IHC) on samples \#5 and \#6. Scale bars $=100 \mu \mathrm{m}$. B. Summary of results from RNAseq, qRT-PCR and IHC. C. Correlation of RNAseq $\left(\log _{2}\right.$-transformed normalized reads per million, nRPM) and qRT-PCR $(1 / \Delta \mathrm{Ct})$ results. Samples $\# 5$ and $\# 6$ are indicated. Linear regression trend, Pearson correlation coefficient $(\mathrm{R})$ and $p$ value are reported. D. Correlation of RNAseq ( $\log _{2}$-transformed normalized reads per million, $\left.\mathrm{nRPM}\right)$ and IHC $\left(\mathrm{CD} 8^{+} \mathrm{T}\right.$ cells $\left./ \mathrm{mm}^{2}\right)$. Samples \#5 and \#6 are indicated; Pearson correlation coefficient (R) and $p$ value are reported. See also Supplementary Figure S2. 
fixation. We are currently focusing on a subset of these genes to generate a focused RNAseq panel (which we named Immune Advance) that predict clinical response to ICBs.

Here, we present data demonstrating that the Immune Advance assay on FFPE samples is associated with a low failure rate and produces gene expression profiles that are highly concordant with those obtained on FF specimens. Moreover, we report that the expression levels of three prototypic biomarkers, namely CTAG1B (a tumor-associated antigen best known as NY-ESO-1) [29], CD8 (a biomarker of cytotoxic T lymphocytes) [30, 31], and PD-L1 (see above) [32], measured by RNAseq, quantitative RT-PCR (qRT-PCR) and immunohistochemistry (IHC) exhibit high levels of correlation. Thus, the Immune Advance assay can accurately profile gene expression in FFPE samples as an instrument to predict clinical response to ICBs.

\section{RESULTS}

\section{Reproducibility of the immune advance assay}

RNA was extracted on matched FFPE and FF sections from 14 ovarian cancer specimens (Figure 1A), and analyzed across three RNAseq runs. The average mean read length was $112 \mathrm{bp}$ and the percentage of aligned bases was 96\% (Supplementary Table S1). All samples had a minimum mapped reads of 2,554,065 with the exception of one sample, 14-FFPE, with 2,354 mapped reads (Supplementary Table S2), which failed our internal quality control. On average, we achieved 4,432,474 mapped reads (after excluding sample 14FFPE), which represents a sufficient depth for digital gene expression profiling of 395 genes. Likewise, $89.55 \%$ mapped reads were on target, which is consistent with best RNAseq practice [33]. Overall 27/28 samples passed quality control, indicating $100 \%$ and $93 \%$ assay robustness for FF and FFPE samples, respectively. Normalized reads per million (nRPM) values derived from each FFPE/FF sample pair were correlated using the Pearson method. The mean, minimum, and maximum Pearson correlation coefficients obtained from 13 paired FFPE/FF samples were 0.920, 0.837, and 0.969 , respectively (Figure $1 \mathrm{~B}$ and Supplementary Figure S1).

\section{Clinical validity}

To obtain insights into the potential clinical application of the Immune Advance assay we compared nRPM values (as obtained by targeted RNAseq) with $\Delta \mathrm{Ct}$
A Sample \#12

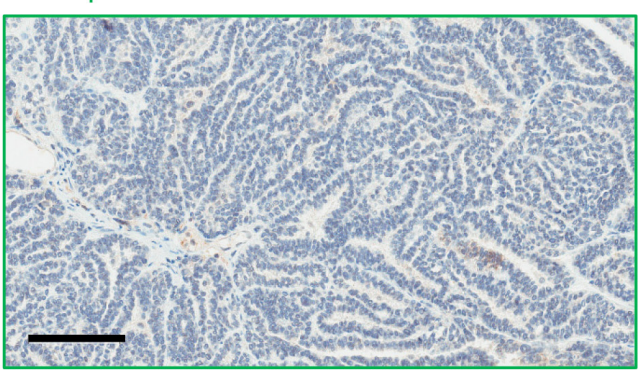

Sample \#10

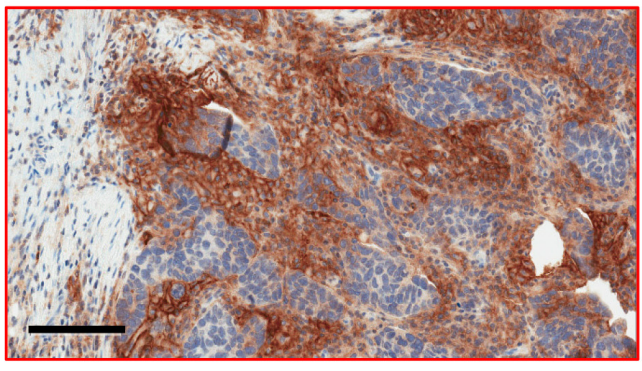

B

\begin{tabular}{|c|c|c|c|c|}
\cline { 2 - 5 } \multicolumn{1}{c|}{} & RNAseq & qRT-PCR & \multicolumn{2}{c|}{ IHC } \\
\hline Sample \# & nRPM $\left(\mathbf{l o g}_{2}\right)$ & $\mathbf{1 / \Delta C t}$ & $\begin{array}{c}\text { \% PD-L1+ cancer } \\
\text { cells }\end{array}$ & $\begin{array}{c}\text { 22C3 pharmDx } \\
\text { Dako }\end{array}$ \\
\hline 10 & 8.4 & 0.152 & $35 \%$ & Negative \\
\hline 6 & 7.2 & 0.119 & $100 \%$ & Positive \\
\hline 5 & 6.9 & 0.116 & $20 \%$ & Negative \\
\hline 8 & 6.5 & 0.108 & $5 \%$ & Negative \\
\hline 7 & 6.0 & 0.103 & $0 \%$ & Negative \\
\hline 13 & 5.8 & 0.114 & $0 \%$ & Negative \\
\hline 11 & 5.5 & 0.101 & $0 \%$ & Negative \\
\hline 2 & 5.4 & 0.096 & $0 \%$ & Negative \\
\hline 4 & 5.2 & 0.102 & $0 \%$ & Negative \\
\hline 9 & 5.0 & 0.111 & $0 \%$ & Negative \\
\hline 1 & 4.4 & 0.080 & $0 \%$ & Negative \\
\hline 12 & 4.3 & 0.085 & $0 \%$ & Negative \\
\hline 3 & 3.6 & 0.084 & $0 \%$ & Negative \\
\hline
\end{tabular}

C

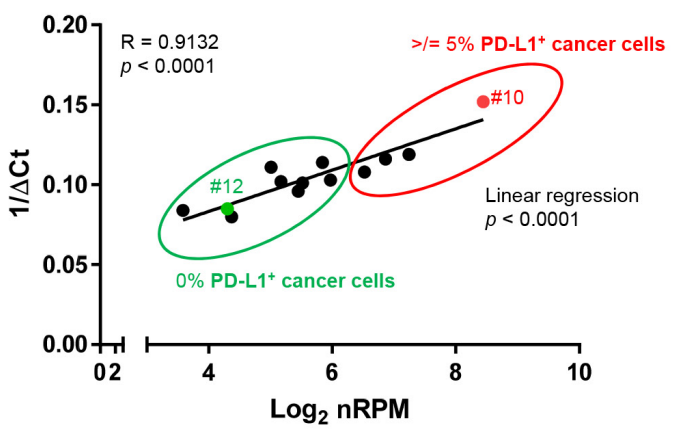

Figure 4: Validation of the Immune Advance assay on PD-L1. A-C. Formalin-fixed paraffin embedded (FFPE) samples from 13 ovarian cancer patients were sectioned and processed for immunohistochemical assessment of PD-L1 expression, RNA extraction followed by targeted RNAseq on a panel of immunological transcripts or qRT-PCR-assisted quantification of CD274 (PD-L1-coding) mRNA levels (GAPDH expression was monitored as internal reference). A. Representative images of PD-L1 expression as assessed by immunohistochemistry (IHC) on samples \#10 and \#12. Scale bars $=100 \mu \mathrm{m}$. B. Summary of results from RNAseq, qRT-PCR and IHC. IHC scoring as per Dako HC223 pharmDx guidelines is indicated. C. Correlation of RNAseq $\left(\log _{2}\right.$-transformed normalized reads per million, $\mathrm{nRPM})$ and qRT-PCR $(1 / \Delta \mathrm{Ct})$ results. Samples $\# 10$ and $\# 12$ are indicated; circles delineate samples with negative $(0 \%)$ or positive $(\geq 5 \%)$ PD-L1 staining by IHC. Linear regression trend, Pearson correlation coefficient (R) and $p$ value are reported. 
values (as obtained by qRT-PCR) for NY-ESO-1, CD8 and PD-L1, finding robust correlation coefficients of $0.9402(p$ $<0.0001), 0.9063(p<0.0001)$ and $0.9132(p<0.0001)$, respectively (Figures 2-4). The immunohistochemical assessment of NY-ESO-1 levels identified 2/14 (14\%) positive samples, with sample \#2 expressing NY-ESO-1 in $5 \%$ of neoplastic cells, and sample \#7 in its totality. nRPM values also highlighted a similar binary distribution of positive versus negative samples, and RNAseq results correlated with both qRT-PCR and IHC findings, although the analysis was limited by the presence of only two positive specimens (Figure 2A-2C).

The expression of CD8 as determined by RNAseq and IHC was regularly distributed across specimens, which facilitated correlation studies. For example, while sample \#5 exhibited $761 \mathrm{CD}^{+} \mathrm{T}$ cells $/ \mathrm{mm}^{2}$, sample \#6 only exhibited $26 \mathrm{CD}^{+} \mathrm{T}$ cells $/ \mathrm{mm}^{2}$. $\log _{2}$-transformed $\mathrm{nRPM}$ and $1 / \Delta \mathrm{Ct}$ values for CD8 linearly correlated with each other over a continuous range (4.1-10.1 $\log _{2} \mathrm{nRPM}$, $0.88-0.1761 / \Delta \mathrm{Ct}$ ) with the standalone exception of sample \#8 (Figure 3A-3C). This specimen was incorrectly scored as containing $1019 \mathrm{CD}^{+} \mathrm{T}$ cells $/ \mathrm{mm}^{2}$ owing to a section folding artifact (Supplementary Figure S2). Excluding sample \#8, the number of $\log _{2}$-transformed CD8 ${ }^{+} \mathrm{T}$ cells/ $\mathrm{mm}^{2}$ significantly correlated with $\log _{2}$-transformed nRPM values $(p<0.0001)$ (Figure 3D).

Finally, four samples exhibited some degree of membranous PD-L1 staining in 5\%-100\% neoplastic cells. These specimens (namely, samples \#5, \#6, \#8 and \#10) also exhibited high nRPM values. Interestingly, the specimen with the highest amount of PD-L1-encoding RNA as per the Immune Advance assay, namely sample $\# 10$, only contained $35 \%{\mathrm{PD}-\mathrm{L}^{+}}^{+}$neoplastic cells. It is important to recognize that sample \#10 would be considered a negative result according to the HC223 pharmDx scoring guidelines. $\log _{2}$-transformed nRPM and $1 / \Delta C t$ values for PD-L1 exhibited robust linear correlation, implying that the expression of this clinicallyrelevant biomarker is not binary like that of NY-ESO-1, but rather continuous such as that of CD8 (Figure 4A-4C).

\section{DISCUSSION}

To assess the usefulness of RNAseq in profiling a panel of immune transcripts on FFPE versus FF samples, we utilized a stringent quality control process for tumor heterogeneity that is unique to our study and to the best of our knowledge has never been applied before [34-38]. Tumors were halved as FF and FFPE mirror images with the cut section of each half used for analysis. Basic quality control factors for RNAseq such as mapped reads were consistent for FFPE and FF samples. Paired samples correlated with coefficients ranging from 0.837 to 0.969 . Moreover, as proof of principle, results from RNAseq and qRT-PCR were highly concordant for NY-ESO-1, CD8, and PD-L1. These findings establish the feasibility of measuring a panel of immune transcripts by RNAseq on FFPE samples to develop a biomarker that predict clinical response to ICBs.

Our study also demonstrates the usefulness of a targeted RNAseq panel to replace immunohistochemical markers including CD8 for cytotoxic T lymphocytes, and PD-L1 as predictors of response to ICBs. While there have been numerous publications on the "immunoscore" as a prognostic biomarker for cancer patients [39-41], several obstacles prevent implementation of an IHC-based approach into clinical routine [42]. Moreover, there is disagreement on the definition of a "high" versus a "low" TIL score in absolute terms, as most publications refer to one or a few private or public patient cohorts wherein stratification is based on median values $[30,31]$. Despite a small sample size in our study, our results support the notion that $\mathrm{CD}^{+} \mathrm{T}$ cells can be quantified and their number linearly correlates with $C D 8$ mRNA expression, as determined by RNAseq. Moreover, our RNAseq data support the notion that PD-L1 expression is continuous rather than binary, in contrast with IHC results. Whether there is a post-translational mechanism that operates to control PD-L1 exposure in a binary manner remains to be determined. If this is not the case, the test currently employed in the clinic to measure PD-L1 expression may lack sensitivity and accuracy, which would have a negative impact on patient selection of immunotherapy with ICBs.

Of note, some tumors that stain positively for PDL1 by IHC (including melanoma, NSCLC, renal cell carcinoma, colorectal carcinoma, and castration-resistant prostate cancer) are insensitive to ICBs, suggesting that PD-L1 alone is not a reliable predictor of clinical response [43]. Simultaneously analyzing multiple immunological biomarkers with RNAseq could improve this situation and allow for the identification of a gene signature that reliably identifies patients who will respond to immunotherapy with ICBs. In this study, we were not able to correlate RNAseq data with clinical outcome, owing to the type of specimens we employed (ovarian cancer patients do not receive ICBs as part of the clinical routine). Moreover, our study involved a limited number of patients affected by a single type of tumor, calling for validation experiments in larger and more heterogeneous patient cohorts. Irrespective of these caveats, we did identify a subset of immune transcripts that were co-expressed with PDL1, and we are evaluating these potential biomarkers in cohorts of melanoma, NSCLC and renal carcinoma patients who receive ICBs as part of their treatment. The road to predicting clinical response to ICBs appears to be more complex than the assessment of a single biomarker like PD-L1. Further experimental and clinical validation of the Immune Advance assay is underway to obtain a robust method for simultaneously measuring the expression of multiple immune transcripts from single FFPE samples. We surmise this may pave the way to improve patient selection for immunotherapy with ICBs. 


\section{MATERIALS AND METHODS}

\section{Patients and specimens}

All patients referred to in this report were diagnosed with ovarian cancer and treated at Roswell Park Cancer Institute (RPCI, Buffalo, NY, US). The RPCI institutional board gave explicit approval to the study, and all samples were obtained upon informed consent under an institutional protocol for tissue collection. To control for tumor heterogeneity in an effort to minimize biological variability, freshly procured remnant tissue was sectioned into two approximate halves, one of which was processed as FF in Optimal Cutting Temperature compound, and the other one fixed in formalin and processed as per standard clinical practices. Each half was marked with ink across the surface to maintain original tissue orientation and mounted on slides faced side up (Figure 1). Sections from the mirroring surfaces of both FF and FFPE blocks were cut and stained with hematoxylin and eosin quality review by a qualified pathologist. Additional serial sections were cut for RNA extraction and IHC. A total of 14 matched FFPE/FF pairs corresponding to 28 samples were collected.

\section{RNA extraction}

RNA was extracted from FFPE tissues using the truXTRACTM FFPE RNA Kit (Covaris), as per manufacturer's instructions with modifications. Briefly, lysates from partially lysed tissue samples were processed immediately for RNA extraction. The truXTRAC ${ }^{\mathrm{TM}}$ FFPE RNA Kit is designed for use with the Adaptive Focused Acoustics AFA ${ }^{\mathrm{TM}}$ process. Standard de-crosslinking and column purification steps were performed to remove proteins and other cellular components prior to RNA elution in water. RNA was extracted from FF tissues using the AllPrep DNA/RNA Mini Kit (Qiagen), as per manufacturer's instructions. RNA was quantified by means of the Qubit RNA HS Assay Kit (Thermo Fisher Scientific).

\section{RNAseq library preparation, quantification, pooling and sequencing}

Oncomine $^{\mathrm{TM}}$ Immune Response Research Assay libraries were prepared using the Ion AmpliSeq ${ }^{\mathrm{TM}}$ targeted sequencing technology (Thermo Fisher Scientific), as per manufacturer's instructions. The Assay is a 395 gene panel focused on diverse immunological processes including TCRS, tumor infiltration by immune cells, and other key immune functions (Supplementary Table S3). Briefly, 10 ng RNA was reverse transcribed into cDNA $\left(25^{\circ} \mathrm{C}\right.$, $10 \mathrm{~min} ; 42{ }^{\circ} \mathrm{C}, 60 \mathrm{~min} ; 85^{\circ} \mathrm{C}, 5 \mathrm{~min} ; 4^{\circ} \mathrm{C}$, hold) and targets were amplified $\left(99^{\circ} \mathrm{C}, 2 \mathrm{~min} ; 99^{\circ} \mathrm{C}, 15\right.$ seconds, $60{ }^{\circ} \mathrm{C}, 4 \mathrm{~min}, 19 \mathrm{X} ; 10^{\circ} \mathrm{C}$, hold) with a multiplex immune response primer pool targeting 395 genes. Amplicons were partially digested using the FuPa Reagent $\left(50^{\circ} \mathrm{C}\right.$, $10 \mathrm{~min} ; 55^{\circ} \mathrm{C}, 10 \mathrm{~min} ; 60^{\circ} \mathrm{C}, 20 \mathrm{~min} ; 10^{\circ} \mathrm{C}$, hold for up to one hour). Barcode adapters were ligated to partially digested amplicons $\left(22{ }^{\circ} \mathrm{C}, 30 \mathrm{~min} ; 72{ }^{\circ} \mathrm{C}, 10 \mathrm{~min} ; 10\right.$ ${ }^{\circ} \mathrm{C}$, hold for up to one hour) and purified. Libraries were quantified using the Ion Library Quantification Kit (Applied Biosystems by Life Technologies), as per manufacturer's instructions. Up to 20 libraries normalized to $50 \mathrm{pM}$ were pooled in equal molar amounts prior to enrichment and template preparation using the Ion Chef ${ }^{\mathrm{TM}}$ system (Thermo Fisher Scientific). 200-bp sequencing was performed on the Ion Proton ${ }^{\mathrm{TM}} \mathrm{P} 1 \mathrm{v} 3$ chip (Thermo Fisher Scientific) to obtain 2-3M reads per sample. Absolute digital gene expression counts and nRPM values were generated using the Torrent Suite software (v5.0.2) and the immuneResponseRNA plugin (both from Thermo Fisher Scientific).

\section{Gene expression normalization}

A baseline expression profile for 10 endogenous control genes was established based on average RPM counts from the internal control sample NA12878 across eleven sequencing runs. Following determination of baseline expression levels, test samples were normalized based on the formula $\mathrm{f}(i)=\mathrm{x}(i) / \mathrm{p}(i)$, in which the $i$-th endogenous control represents the fold change $\mathrm{f}(i)$ of the raw read count $\mathrm{x}(i)$ over the above-mentioned baseline profile $\mathrm{p}(i)$. The median of fold changes from all these controls was then determined as $\mathrm{F}=$ median $(\mathrm{f}(i) \mid I=$ $1, \ldots 10)$. This value was further used to normalize RPM counts for all genes in the sample according to the formula $\mathrm{x}^{\prime}(i)=\mathrm{x}(i) / \mathrm{F}$, where $\mathrm{x}(i)$ is the raw read count of the $i$-th gene and $\mathrm{x}^{\prime}(i)$ is the normalized expression (nRPM) value to be used for downstream analysis. Finally, nRPM values were $\log _{2}$-transformed.

\section{Immunohistochemistry}

A $5 \mu$ m thick whole section from each FFPE sample was stained with antibodies specific for NY-ESO-1 (E978, Santa Cruz Biotechnology), PD-L1 (22C3 pharmDx, Dako), and CD8 (C8/144B, Dako), according to standard procedures. NY-ESO-1 and PD-L1 expression was evaluated by a board-certified pathologist who interpreted the staining as positive or negative. For NY-ESO-1, a positive sample was defined by moderate to strong cytoplasmic staining with membranous accentuation that is distinct from background in at least $5 \%$ of neoplastic cells, while a negative sample was defined by staining in $<5 \%$ of neoplastic cells. For PD-L1, a positive sample was defined as per FDA-approved guidelines as partial or complete cell membrane staining $(\geq 1+)$ in $\geq 50 \%$ of viable tumor cells, while a negative samples was defined by any membranous staining in less than $50 \%$ of neoplastic cells. 
$\mathrm{CD}^{+} \mathrm{T}$ lymphocytes were stained and scored using the Aperio Scanscope (Aperio Technologies, Inc.), based on 20X bright-field optical microscopy. Images were analyzed using Spectrum (Aperio Technologies, Inc.) and the number of $\mathrm{CD} 8^{+} \mathrm{T}$ lymphocytes per square millimeter was counted.

\section{Quantitative RT-PCR (qRT-PCR)}

Ten ng RNA was reverse-transcribed $\left(25^{\circ} \mathrm{C}, 10\right.$ min, $37^{\circ} \mathrm{C}$, $120 \mathrm{~min} ; 85^{\circ} \mathrm{C} 5 \mathrm{~min} ; 4^{\circ} \mathrm{C}$, hold), amplified $\left(50^{\circ} \mathrm{C}, 2 \mathrm{~min}, 95^{\circ} \mathrm{C}, 10 \mathrm{~min}, 95^{\circ} \mathrm{C}, 15\right.$ seconds, $60^{\circ} \mathrm{C}, 1$ min, 40X), and $\Delta \mathrm{Ct}$ was determined using TaqMan Gene Expression Assays specific for CTAG1B/1A (NY-ESO-1), CD274 (PD-L1) and CD8 (Thermo Fisher Scientific) on the QuantStudio 7 Real-Time PCR System (Thermo Fisher Scientific). Glyceraldehyde-3-phosphate dehydrogenase $(G A P D H)$ was employed as reference transcript. $\Delta \mathrm{Ct}$ values are depicted as $1 / \Delta \mathrm{Ct}$.

\section{Statistical analysis}

Correlation coefficients were calculated according to the Pearson method. $p$ values $<0.05$ were considered statistically significant. All statistical analyses were conducted on Prism 7 (GraphPad Software).

\section{CONFLICTS OF INTEREST} LLC.

$\mathrm{CM}, \mathrm{JC}$ and $\mathrm{MN}$ hold minor interest in OmniSeq

\section{REFERENCES}

1. Sharma P, Allison JP. The future of immune checkpoint therapy. Science. 2015; 348:56-61.

2. Hodi FS, O'Day SJ, McDermott DF, Weber RW, Sosman JA, Haanen JB, Gonzalez R, Robert C, Schadendorf D, Hassel JC, Akerley W, van den Eertwegh AJ, Lutzky J, et al. Improved survival with ipilimumab in patients with metastatic melanoma. N Engl J Med. 2010; 363:711-723.

3. Robert C, Thomas L, Bondarenko I, O'Day S, Weber J, Garbe C, Lebbe C, Baurain JF, Testori A, Grob JJ, Davidson $\mathrm{N}$, Richards J, Maio M, et al. Ipilimumab plus dacarbazine for previously untreated metastatic melanoma. N Engl J Med. 2011; 364:2517-2526.

4. Wolchok JD, Neyns B, Linette G, Negrier S, Lutzky J, Thomas L, Waterfield W, Schadendorf D, Smylie M, Guthrie T, Jr., Grob JJ, Chesney J, Chin K, et al. Ipilimumab monotherapy in patients with pretreated advanced melanoma: a randomised, double-blind, multicentre, phase 2, dose-ranging study. Lancet Oncol. 2010; 11:155-164.

5. Borghaei H, Paz-Ares L, Horn L, Spigel DR, Steins M, Ready NE, Chow LQ, Vokes EE, Felip E, Holgado E, Barlesi F, Kohlhaufl M, Arrieta O, et al. Nivolumab versus
Docetaxel in Advanced Nonsquamous Non-Small-Cell Lung Cancer. N Engl J Med. 2015; 373:1627-1639.

6. Brahmer J, Reckamp KL, Baas P, Crino L, Eberhardt WE, Poddubskaya E, Antonia S, Pluzanski A, Vokes EE, Holgado E, Waterhouse D, Ready N, Gainor J, et al. Nivolumab versus Docetaxel in Advanced SquamousCell Non-Small-Cell Lung Cancer. N Engl J Med. 2015; 373:123-135.

7. Motzer RJ, Escudier B, McDermott DF, George S, Hammers HJ, Srinivas S, Tykodi SS, Sosman JA, Procopio G, Plimack ER, Castellano D, Choueiri TK, Gurney H, et al. Nivolumab versus Everolimus in Advanced Renal-Cell Carcinoma. N Engl J Med. 2015; 373:1803-1813.

8. Postow MA, Chesney J, Pavlick AC, Robert C, Grossmann K, McDermott D, Linette GP, Meyer N, Giguere JK, Agarwala SS, Shaheen M, Ernstoff MS, Minor D, et al. Nivolumab and ipilimumab versus ipilimumab in untreated melanoma. N Engl J Med. 2015; 372:2006-2017.

9. Robert C, Long GV, Brady B, Dutriaux C, Maio M, Mortier L, Hassel JC, Rutkowski P, McNeil C, Kalinka-Warzocha E, Savage KJ, Hernberg MM, Lebbe C, et al. Nivolumab in previously untreated melanoma without BRAF mutation. $\mathrm{N}$ Engl J Med. 2015; 372:320-330.

10. Wolchok JD, Kluger H, Callahan MK, Postow MA, Rizvi NA, Lesokhin AM, Segal NH, Ariyan CE, Gordon RA, Reed K, Burke MM, Caldwell A, Kronenberg SA, et al. Nivolumab plus ipilimumab in advanced melanoma. N Engl J Med. 2013; 369:122-133.

11. Garon EB, Rizvi NA, Hui R, Leighl N, Balmanoukian AS, Eder JP, Patnaik A, Aggarwal C, Gubens M, Horn L, Carcereny E, Ahn MJ, Felip E, et al. Pembrolizumab for the treatment of non-small-cell lung cancer. N Engl J Med. 2015; 372:2018-2028.

12. Ribas A, Puzanov I, Dummer R, Schadendorf D, Hamid O, Robert C, Hodi FS, Schachter J, Pavlick AC, Lewis KD, Cranmer LD, Blank CU, O'Day SJ, et al. Pembrolizumab versus investigator-choice chemotherapy for ipilimumabrefractory melanoma (KEYNOTE-002): a randomised, controlled, phase 2 trial. Lancet Oncol. 2015; 16:908-918.

13. Robert C, Ribas A, Wolchok JD, Hodi FS, Hamid O, Kefford R, Weber JS, Joshua AM, Hwu WJ, Gangadhar TC, Patnaik A, Dronca R, Zarour H, et al. Anti-programmeddeath-receptor-1 treatment with pembrolizumab in ipilimumab-refractory advanced melanoma: a randomised dose-comparison cohort of a phase 1 trial. Lancet. 2014; 384:1109-1117.

14. Robert C, Schachter J, Long GV, Arance A, Grob JJ, Mortier L, Daud A, Carlino MS, McNeil C, Lotem M, Larkin J, Lorigan P, Neyns B, et al. Pembrolizumab versus Ipilimumab in Advanced Melanoma. N Engl J Med. 2015; 372:2521-2532.

15. McDermott DF, Sosman JA, Sznol M, Massard C, Gordon MS, Hamid O, Powderly JD, Infante JR, Fasso M, Wang YV, Zou W, Hegde PS, Fine GD, et al. Atezolizumab, an Anti-Programmed Death-Ligand 1 Antibody, in Metastatic 
Renal Cell Carcinoma: Long-Term Safety, Clinical Activity, and Immune Correlates From a Phase Ia Study. J Clin Oncol. 2016; 34:833-842.

16. Rosenberg JE, Hoffman-Censits J, Powles T, van der Heijden MS, Balar AV, Necchi A, Dawson N, O'Donnell $\mathrm{PH}$, Balmanoukian A, Loriot Y, Srinivas S, Retz MM, Grivas P, et al. Atezolizumab in patients with locally advanced and metastatic urothelial carcinoma who have progressed following treatment with platinum-based chemotherapy: a single-arm, multicentre, phase 2 trial. Lancet. 2016; 387:1909-1920.

17. Topalian SL, Taube JM, Anders RA, Pardoll DM. Mechanism-driven biomarkers to guide immune checkpoint blockade in cancer therapy. Nat Rev Cancer. 2016; 16:275-287.

18. Webster RM. The immune checkpoint inhibitors: where are we now? Nat Rev Drug Discov. 2014; 13:883-884.

19. Patel SP, Kurzrock R. PD-L1 Expression as a Predictive Biomarker in Cancer Immunotherapy. Mol Cancer Ther. 2015; 14:847-856.

20. Roach C, Zhang N, Corigliano E, Jansson M, Toland G, Ponto G, Dolled-Filhart M, Emancipator K, Stanforth D, Kulangara K. Development of a Companion Diagnostic PD-L1 Immunohistochemistry Assay for Pembrolizumab Therapy in Non-Small-cell Lung Cancer. Appl Immunohistochem Mol Morphol. 2016; 24:392-397.

21. Gubin MM, Zhang X, Schuster H, Caron E, Ward JP, Noguchi T, Ivanova Y, Hundal J, Arthur CD, Krebber WJ, Mulder GE, Toebes M, Vesely MD, et al. Checkpoint blockade cancer immunotherapy targets tumour-specific mutant antigens. Nature. 2014; 515:577-581.

22. Rizvi NA, Hellmann MD, Snyder A, Kvistborg P, Makarov V, Havel JJ, Lee W, Yuan J, Wong P, Ho TS, Miller ML, Rekhtman N, Moreira AL, et al. Cancer immunology. Mutational landscape determines sensitivity to PD-1 blockade in non-small cell lung cancer. Science. 2015; 348:124-128.

23. Snyder A, Makarov V, Merghoub T, Yuan J, Zaretsky JM, Desrichard A, Walsh LA, Postow MA, Wong P, Ho TS, Hollmann TJ, Bruggeman C, Kannan K, et al. Genetic basis for clinical response to CTLA-4 blockade in melanoma. N Engl J Med. 2014; 371:2189-2199.

24. Hamid O, Schmidt H, Nissan A, Ridolfi L, Aamdal S, Hansson J, Guida M, Hyams DM, Gomez H, Bastholt L, Chasalow SD, Berman D. A prospective phase II trial exploring the association between tumor microenvironment biomarkers and clinical activity of ipilimumab in advanced melanoma. J Transl Med. 2011; 9:204.

25. Herbst RS, Soria JC, Kowanetz M, Fine GD, Hamid O, Gordon MS, Sosman JA, McDermott DF, Powderly JD, Gettinger SN, Kohrt HE, Horn L, Lawrence DP, et al. Predictive correlates of response to the anti-PD-L1 antibody MPDL3280A in cancer patients. Nature. 2014; 515:563-567.
26. Tumeh PC, Harview CL, Yearley JH, Shintaku IP, Taylor EJ, Robert L, Chmielowski B, Spasic M, Henry G, Ciobanu V, West AN, Carmona M, Kivork C, et al. PD-1 blockade induces responses by inhibiting adaptive immune resistance. Nature. 2014; 515:568-571.

27. Medeiros F, Rigl CT, Anderson GG, Becker SH, Halling $\mathrm{KC}$. Tissue handling for genome-wide expression analysis: a review of the issues, evidence, and opportunities. Arch Pathol Lab Med. 2007; 131:1805-1816.

28. Penland SK, Keku TO, Torrice C, He X, Krishnamurthy J, Hoadley KA, Woosley JT, Thomas NE, Perou CM, Sandler RS, Sharpless NE. RNA expression analysis of formalin-fixed paraffin-embedded tumors. Lab Invest. 2007; 87:383-391.

29. Odunsi K, Jungbluth AA, Stockert E, Qian F, Gnjatic S, Tammela J, Intengan M, Beck A, Keitz B, Santiago D, Williamson B, Scanlan MJ, Ritter G, et al. NY-ESO-1 and LAGE-1 cancer-testis antigens are potential targets for immunotherapy in epithelial ovarian cancer. Cancer Res. 2003; 63:6076-6083.

30. Senovilla L, Vacchelli E, Galon J, Adjemian S, Eggermont A, Fridman WH, Sautes-Fridman C, Ma Y, Tartour E, Zitvogel L, Kroemer G, Galluzzi L. Trial watch: Prognostic and predictive value of the immune infiltrate in cancer. Oncoimmunology. 2012; 1:1323-1343.

31. Fridman WH, Pages F, Sautes-Fridman C, Galon J. The immune contexture in human tumours: impact on clinical outcome. Nat Rev Cancer. 2012; 12:298-306.

32. Zou W, Chen L. Inhibitory B7-family molecules in the tumour microenvironment. Nat Rev Immunol. 2008; 8:467-477.

33. Conesa A, Madrigal P, Tarazona S, Gomez-Cabrero D, Cervera A, McPherson A, Szczesniak MW, Gaffney DJ, Elo LL, Zhang X, Mortazavi A. A survey of best practices for RNA-seq data analysis. Genome Biol. 2016; 17:13.

34. Auerbach SS, Phadke DP, Mav D, Holmgren S, Gao Y, Xie B, Shin JH, Shah RR, Merrick BA, Tice RR. RNASeq-based toxicogenomic assessment of fresh frozen and formalin-fixed tissues yields similar mechanistic insights. J Appl Toxicol. 2015; 35:766-780.

35. Hedegaard J, Thorsen K, Lund MK, Hein AM, HamiltonDutoit SJ, Vang S, Nordentoft I, Birkenkamp-Demtroder K, Kruhoffer M, Hager H, Knudsen B, Andersen CL, Sorensen $\mathrm{KD}$, et al. Next-generation sequencing of RNA and DNA isolated from paired fresh-frozen and formalin-fixed paraffin-embedded samples of human cancer and normal tissue. PLoS One. 2014; 9:e98187.

36. Li P, Conley A, Zhang H, Kim HL. Whole-Transcriptome profiling of formalin-fixed, paraffin-embedded renal cell carcinoma by RNA-seq. BMC Genomics. 2014; 15:1087.

37. Norton N, Sun Z, Asmann YW, Serie DJ, Necela BM, Bhagwate A, Jen J, Eckloff BW, Kalari KR, Thompson KJ, Carr JM, Kachergus JM, Geiger XJ, et al. Gene expression, single nucleotide variant and fusion transcript discovery 
in archival material from breast tumors. PLoS One. 2013; 8:e81925.

38. Webster AF, Zumbo P, Fostel J, Gandara J, Hester SD, Recio L, Williams A, Wood CE, Yauk CL, Mason CE. Mining the Archives: A Cross-Platform Analysis of Gene Expression Profiles in Archival Formalin-Fixed ParaffinEmbedded Tissues. Toxicol Sci. 2015; 148:460-472.

39. Galon J, Costes A, Sanchez-Cabo F, Kirilovsky A, Mlecnik B, Lagorce-Pages C, Tosolini M, Camus M, Berger A, Wind P, Zinzindohoue F, Bruneval P, Cugnenc PH, et al. Type, density, and location of immune cells within human colorectal tumors predict clinical outcome. Science. 2006; 313:1960-1964.

40. Mlecnik B, Bindea G, Kirilovsky A, Angell HK, Obenauf AC, Tosolini M, Church SE, Maby P, Vasaturo A, Angelova M, Fredriksen T, Mauger S, Waldner M, et al. The tumor microenvironment and Immunoscore are critical determinants of dissemination to distant metastasis. Sci Transl Med. 2016; 8:327ra326.

41. Mlecnik B, Tosolini M, Kirilovsky A, Berger A, Bindea G, Meatchi T, Bruneval P, Trajanoski Z, Fridman WH, Pages F, Galon J. Histopathologic-based prognostic factors of colorectal cancers are associated with the state of the local immune reaction. J Clin Oncol. 2011; 29:610-618.

42. Galon J, Pages F, Marincola FM, Angell HK, Thurin M, Lugli A, Zlobec I, Berger A, Bifulco C, Botti G, Tatangelo F, Britten CM, Kreiter S, et al. Cancer classification using the Immunoscore: a worldwide task force. J Transl Med. 2012; 10:205.

43. Taube JM, Klein A, Brahmer JR, Xu H, Pan X, Kim JH, Chen L, Pardoll DM, Topalian SL, Anders RA. Association of PD-1, PD-1 ligands, and other features of the tumor immune microenvironment with response to anti-PD-1 therapy. Clin Cancer Res. 2014; 20:5064-5074. 